\title{
Retos y oportunidades para la inclusión de la población gitana más vulnerable: un acercamiento desde la experiencia navarra ${ }^{1}$
}

\section{Víctor Sánchez Salmerón}

Departamento de Sociología y Trabajo Social, Universidad Pública de Navarra victor.sanchez@unavarra.es

\begin{abstract}
Gizarteratzeko baliabideetan eta Nafarroako dirusarrerak bermatzeko programan parte hartzen duten ijitoen bizi-kontakizunen analisiaren bidez, artikulu hau baztertuen bizi den biztanleria multzoarekin, zailtasun gehien pilatzen dituena, nola la egiten den aztertzen da. o\} Premisaren arabera, ijitoen problematikari aurre egiteko erakundeek dituzten mugak azter daitezke, eta aldi berean gizarteratzepolitiken zenbait ahulezia ezagutu, baina ez soilik ijito diren biztanleen kasuan, baita gizarteratutako beste biztanleen kasuan ere. Testuaren azken zatian, ijitoen etxe askotan gizarteratze-neurrien eraginkortasuna hobetzeko proposamen batzuk aurkezten dira, eta talde gutxitu horrek arreta hobea izateak nahitaez biztanleria kalteberarengan ere eragina izan dezakeela.
\end{abstract}

\section{GAKO-HITZAK:}

Biztanleria ijitoa, gizarteratzea, talde gutxituak, bazterkeria, pobrezia.

\begin{abstract}
A través del análisis de relatos de vida de la población gitana participante en recursos de inclusión y en el programa de garantía de ingresos de Navarra, este artículo trata de aproximarse al modo en que opera este escenario con el sector de la población más excluido y en el que se acumulan más dificultades. La premisa es que en ello se puede analizar las limitaciones de la respuesta institucional ante la cuestión gitana y, al mismo tiempo, recoger algunas de las debilidades de las políticas de inclusión, no solo en la acción con la población gitana, sino también con el resto de población includenda. En la parte final del texto se presentan algunas propuestas que podrían mejorar la eficacia de las medidas de inclusión en muchos hogares gitanos, sabiendo que la promoción de una mejor atención para la minoría repercute necesariamente también en el resto de la población vulnerable.
\end{abstract}

\section{Palabras Clave:}

Población gitana, inclusión social, minorías, exclusión, pobreza. 


\section{La articulación del modelo de integración de la minoría gitana en el ámbito estatal}

En las últimas décadas el interés por la situación de la población gitana ha ido adquiriendo mayor notoriedad en la agenda política y social. La reciente proliferación de estrategias y planes de inclusión a nivel regional y estatal enfocados específicamente sobre esta minoría son una clara expresión de ello en nuestro país. Y aunque este desarrollo normativo ha estado dirigido especialmente hacia aquel sector que se encuentra ante mayores dificultades, también este impulso ha venido acompañado de acciones e iniciativas de promoción y reconocimiento de la cultura e identidad gitana.

Sin embargo, esta voluntad por equiparar el estatus ciudadano y las condiciones de vida y de bienestar de la población minoritaria con las de la mayoría tiene un largo recorrido en nuestro país. Ya en 1982 la Asociación Nacional Presencia Gitana elaboró a petición del Partido Socialista un Informe sobre la cuestión gitana (1991) con el que se trataba de aportar algunas claves para abordar la problemática situación de gran parte de la comunidad en el nuevo y alentador escenario democrático. En esa misma década, en 1985, se pondría en marcha el Plan Nacional de Desarrollo Gitano, al que proseguiría en 1989 el Programa de Desarrollo Gitano, principal instrumento económico de la política social para con la minoría a nivel estatal y todavía vigente.

Dichos hitos ponían de manifiesto en aquel contexto un inequívoco interés por enfocar con significado y enfoque propio el conjunto de situaciones que aluden a aquella parte de la población gitana que padece mayores privaciones, tal y como se venía haciendo en algunas otras naciones europeas desde mediados del siglo XX. En los países centroeuropeos, bajo la locución "cuestión gitana" se venían agrupando el conjunto de medidas emprendidas para tratar de incorporar a la minoría en la organización estatal y económica. Inicialmente, con un claro enfoque centrado en la trasformación de los individuos gitanos, pero más adelante, en las dos últimas décadas del siglo, al menos en lo discursivo, considerando las cuestiones estructurales y sistémicas que excluyen a los miembros de la minoría por su condición étnica y eludiendo aquellas prácticas abiertamente asimilacionistas (Montesino, 2012; Montesino y Ohlsson, 2015; Willems, 1997).

Con todo, la implementación de medidas relacionadas con la población gitana en nuestro país se anticipó varias décadas al impulso -ya en el presente siglodel tema gitano en la agenda social europea, pero llegaba tarde en comparación con la tecnificación y profesionalización de la intervención social propia de los Estados de Bienestar de nuestro entorno. A la postre, este particular panorama de políticas y medidas permitió el desarrollo de una experiencia para con la minoría diferenciada con respecto a las inercias y dinámicas europeas. En lo sucesivo, fue adquiriendo forma lo que se ha llegado a definir como el modelo de integración/inclusión de la población gitana española (Fundación Secretariado Gitano, 2012), y que se ha articulado fundamentalmente en torno a dos pilares. La población gitana se ha beneficiado del desarrollo del Estado de Bienestar a lo largo de las últimas décadas. Adicionalmente, esta participación se ha complementado con el desarrollo de medidas específicas para favorecer el acceso a los sistemas de protección y bienestar dirigidos de aquellas personas que tienen más dificultades o que requieren de una atención más intensa por su grave situación de desventaja.

El modelo en sí no se aleja de la lógica de trabajo empleada con el resto de población en dificultad. Debido a que los procesos de exclusión y empobrecimiento obedecen a factores que se producen a nivel estructural, institucional e individual, las acciones para contrarrestarlos se han venido acometiendo en cada uno de ellos. Existe cierto consenso en considerar que las políticas de inclusión se despliegan en esencia en estos dos últimos niveles, e implican la acción de los sistemas de servicios sociales y de empleo principalmente (políticas de acceso al empleo, de garantía de ingresos, servicios personales, etc.), así como las medidas de intervención con familias e individuos vulnerables para favorecer su autonomía, funcionalidad o mejorar su participación social (Pérez Eransus, 2016).

En los dos primeros niveles (macro y meso), la acción se ha desarrollado bajo la premisa de centrarse explícitamente pero no exclusivamente en la minoría, para evitar la etnificación de los apoyos -que se brindan en función de la situación objetiva de necesidad-y la estigmatización de la minoría. Es a nivel micro donde se han llevado a cabo la mayoría de las acciones expresamente dirigidas a los individuos de la comunidad gitana, y desde donde se han desplegado las medidas de discriminación positiva, impulsadas tanto por los actores públicos como por entidades privadas del tercer sector de acción social, en muchas ocasiones con apoyo del erario común.

Con todo, bajo este paradigma la situación de una parte importante de la minoría en nuestro país ha percibido notables avances, sobre todo en lo que respecta a la dignificación de su situación residencial y a la normalización en el acceso a los servicios y prestaciones del sistema de protección social. Las pasadas décadas pueden valorarse en términos de progreso para la comunidad gitana, aunque no está tan claro que este progreso haya mantenido la misma intensidad que para el resto de población, ni haya alcanzado a toda la minoría, hecho especialmente visible en la sobrerrepresentación de la minoría en el espacio de la exclusión social y de la pobreza que durante todo este tiempo se ha mantenido constante (Laparra y Pérez Eransus, 2008), y en el desigual impacto de la crisis, más pronunciado si cabe en el caso de la minoría gitana (Damonti y Arza, 2014). 
El modelo, por lo tanto, no siempre ha contado con una atención y provisión de recursos acordes a la intensidad de las situaciones de necesidad que ha padecido la minoría. En la actualidad muestra además visos de cierto agotamiento. Los grandes cambios acaecidos en el escenario de la exclusión social en las últimas décadas y la vinculación de la minoría con una de las principales categorías de riesgo social (Gil Calvo, 2009) han minorado el potencial integrador de los sistemas universales de bienestar. El modelo se ve igualmente afectado por la inhibición de las políticas de inclusión dirigidas al conjunto de la población de las que participa una buena parte de la comunidad en situación de dificultad. También por el deterioro de las posibilidades económicas de la minoría. Si a finales del siglo pasado algunas de las denominadas "actividades tradicionales" de la minoría todavía ofrecían un nivel aceptable de ingresos y de nivel de vida, en la actualidad esta capacidad está fuertemente en entredicho.

Por otro lado, la evolución del modelo tampoco ha sido constante y ha mantenido un desarrollo episódico y secundario. Sin embargo, de un tiempo a esta parte se han concitado dos tendencias a muy distinto nivel que le han devuelto cierta notoriedad. En primer lugar, debido a la transferencia de competencias en materia de inclusión hacia las comunidades autónomas, la intervención con la minoría ha ido planificándose cada vez más desde el ámbito territorial. En paralelo, ha ido aumentando también la atención a nivel supraestatal, donde el modelo de intervención español ha gozado de cierta posición referencial.

\section{El modelo español de integración en el escenario europeo}

En efecto, también en el continente europeo la situación de exclusión de la población romaní adquirió cierta relevancia bien entrada la década de los noventa. En este caso fueron sobre todo las organizaciones no gubernamentales quienes comenzaron a ver con preocupación la extensa distancia de la minoría con respecto al resto de la ciudadanía. Estas entidades tendrán un importante papel en la denuncia de la acentuada desigualdad padecida por la minoría y de la proliferación de actuaciones discriminatorias por algunos gobiernos estatales.

La ampliación de la Unión Europea hacia el Este (2004-2007) y el aumento del peso demográfico de la población gitana dentro de sus fronteras supuso un punto de inflexión en el escenario europeo. El hito para que la cuestión gitana emergiera con fuerza en la arena política se encontró en la trasformación de la población gitana de la posición de minorías nacionales a la condición de potenciales migrantes (Sigona, 2010). La tensión migratoria resultó trascendental, pero no solo. También la situación del pueblo gitano autóctono en los países occidentales lastraba notables dificultades socioeconómicas. En algunos territorios incluso se percibía un sensible aumento de la conflictividad interétnica (sobre todo con la población gitana no asentada) y de las prácticas discriminatorias. El llamamiento para la inclusión de la población romaní por parte del Parlamento Europeo en 2008 interpelaba a prácticamente todas las naciones europeas, convirtiendo así la cuestión, en principio, en una prioridad en la agenda política de la Unión Europea ${ }^{2}$. Uno de los precedentes para una acción paneuropea lo supuso la Decade of Roma Inclusion (2005-2015), iniciativa de carácter privado que aunó el esfuerzo de distintos actores e instituciones para incorporar definitivamente la problemática gitana en la agenda y en el debate público y, en cierta medida, para prevenir las pérdidas económicas y demográficas que supondría la exclusión y emigración de la minoría en los países del Este. La mayoría de las evaluaciones realizadas al término de su desarrollo señalaban los escasos avances logrados en todas y cada una de las áreas de acción propuestas (Szira, 2015; Rorke, 2015b). Entre las principales causas que motivaron este reducido impacto habría que listar en muchos países, como en el nuestro, que la iniciativa se desarrolló en pleno impacto de la crisis de 2008. No obstante, se pusieron en marcha contribuciones inéditas. La iniciativa ayudo a definir prioridades en materia de inclusión y a impulsar el compromiso con la cuestión gitana a nivel internacional.

Por otro lado, la experiencia española en la integración de la población gitana ha gozado de cierta posición referencial en el proceso de europeización de la cuestión. Entre los factores que explican este hecho se pueden señalar, en primer lugar, la mejor situación de la comunidad gitana en nuestro país en términos comparativos con la del resto del continente, especialmente con respecto a la población romaní de Europa del Este, sin que ello oscurezca el mantenimiento de importantes dificultades también en nuestro entorno. La convivencia entre la mayoría y la minoría también ha sido en buena medida disonante con respecto a la tónica general de nuestro entorno. Si bien la población gitana en España sigue copando el rechazo de la mayoría, tal y como queda evidenciado sistemáticamente en los barómetros y encuestas de discriminación al uso (Arza y Carrón, 2015), la tensión interétnica no ha alcanzado las cotas de conflictividad de otros países (no solo del Este, sino también en otros más próximos como Francia e Italia), donde se han decretado expulsiones de grupos y familias itinerantes incluso al mismo tiempo que se planificaba la agenda europea para la minoría. De conformidad con Liégeois, la experiencia histórica en el caso peninsular se ha caracterizado por contemplar más intentos de integración y asentamiento forzoso a lo largo del tiempo, lo que ha provocado que el nivel

${ }^{2}$ La cuestión gitana se había introducido previamente de manera oficial en 2005. La cámara dictó dos resoluciones centradas en la situación de la población gitana en la unión durante 2005 y 2006. La primera centrada en la situación de la minoría en su conjunto y la segunda en el caso concreto de las mujeres gitanas. 
de asimilación y cohesión sea más alto que en otros países (Utrera, 1987), explicando en parte este menor nivel de conflictividad.

Tanto o más significativa fue la presidencia española de la Unión Europea durante el primer semestre de 2010, ya que ejerció una labor central en la consolidación de la cuestión gitana en la agenda europea (Tsolakis, 2011). Apoyándose en la larga experiencia española con la minoría, durante el mandato se definieron objetivos y se establecieron prioridades en el plano político. La presidencia fue determinante para integrar en la política europea los diez principios básicos comunes, fuertemente inspirados en el modelo español (Comisión Europea, 2009). En todo caso, no se ha tratado de un trasvase unidireccional. También el marco europeo ha revertido en la consolidación del modelo estatal al dotarlo de más fuentes de financiación europea (principalmente a través del Fondo Social Europeo) y mediante el intercambio de conocimientos y buenas prácticas entre los países.

La agenda europea no ha estado exenta de críticas. Entre las opiniones más radicales se encuentran aquellas que sostienen que la propuesta, al relegar a un segundo plano los debates sobre el impulso de medidas de corte estructural y reducir la acción inclusiva a la inserción individual, atribuye exclusivamente a los miembros de la minoría la responsabilidad para transformar su situación. Perspectiva que pone en cuestión el derecho a la diferencia de la minoría de manera implícita (Gamella, 1996), puesto que, como ha sido sostenido en ocasiones, la inclusión tiene un "lado oscuro" que puede implicar coerción para unirse y asimilarse a las prácticas y valores del grupo dominante (Daly y Silver, 2008). De igual modo, el énfasis en la necesidad de una atención específica para la minoría no haría sino aumentar la distancia simbólica entre la mayoría y la minoría, lo que no sería sino contraproducente para lograr una genuina inclusión en la sociedad (Rorke, 2014).

Por otro lado, también se ha señalado que vincular entre sí a la población romaní a lo largo de todo el continente, convirtiéndola en la gran minoría trasnacional para justificar una intervención coordinada en los Estados miembro, podría tener algunas implicaciones que pueden incluso resultar negativas para los intereses del activismo gitano y la población gitana. Como advierte Vermeersch (2012) puede darse la paradoja de que entender la cuestión gitana como un asunto europeo inhiba la responsabilidad de la política nacional, escudándose esta en que los asuntos europeos competen a las instituciones europeas.

\section{La centralidad de las respuestas autonómicas en la inclusión de la minoría gitana}

En el caso español no está nada claro que se haya producido esta dejación deliberada de responsabilidades por parte de la Administración estatal. De hecho, se ha asumido en alto grado la idea de que la cuestión gitana es un asunto público, esto es, que no concierne exclusivamente a la minoría, sino que interpela a distintos actores de la Administración Pública, como también a las entidades privadas del tercer sector que tan importante papel han tenido en el desarrollo de la comunidad gitana, especialmente en aquellos espacios urbanos más segregados donde la intervención gubernamental ha tenido baja o muy baja intensidad.

Dicho esto, la función de la Administración estatal se supedita al protagonismo de otros niveles gubernamentales en materia de inclusión social. Debido a la considerable descentralización de la política social en nuestro país, las competencias de la Administración central son limitadas para el desarrollo de políticas destinadas a la comunidad gitana. Incluso ya desde el proceso de constitución de los sistemas de servicios sociales, la atención a la diversidad étnica se planteó como una cuestión a desarrollar en el entorno más próximo y local. La concepción comunitaria del sistema en sus planteamientos iniciales habría de permitir la adaptación de la intervención social a las poblaciones de cada territorio (Rodríguez Cabrero et al., 2011), y entre ellas, la gitana.

Esto no implica que los apoyos sectoriales o dirigidos a la minoría vayan a estar exclusivamente gestionados e impulsados por las Administraciones locales o autonómicas. Actores e instituciones a distinto nivel mantienen competencias y responsabilidades en su desarrollo. De hecho, los recursos dispuestos por la Administración central se adaptan a esta estructura, como es el caso del Programa de Desarrollo Gitano. Esencialmente el programa dispone una partida presupuestaria, consignada en los Presupuestos Generales del Estado, a través de la que se impulsan proyectos de intervención social a nivel local y autonómico, en algunos casos coordinados con organizaciones sociales privadas $\mathrm{y} / \mathrm{o}$ del movimiento asociativo gitano. Además del Programa de Desarrollo Gitano se han dispuesto otros organismos como el Grupo de Cooperación Técnica (GCT) que trata de impulsar iniciativas a nivel local y autonómico para la intervención con la población gitana y favorecer el intercambio de conocimiento y experiencias entre territorios.

Así, la fuerte descentralización ha generado diferencias notables entre las regiones con respecto a las políticas destinadas a la minoría (tal y como ocurre, no obstante, con las políticas de inclusión destinadas al conjunto de la población). La respuesta ante la temática gitana a este nivel está fuertemente vinculada con diversos factores de carácter local, como el peso demográfico de la minoría o la capacidad de influencia del asociacionismo gitano en la agenda local y regional. Pero también por el grado de desarrollo y el modelo de políticas de inclusión 
en el territorio, y por la forma que ha adoptado la aproximación a la cuestión gitana, que oscila entre canalizar la atención a la minoría a través de recursos de inserción específicos, o favorecer la participación de la población gitana en las medidas generalistas de incorporación social y laboral dirigidas al conjunto de la población. En este sentido, el modelo de inclusión español no es tan homogéneo como pudiera deducirse del nominal.

La dificultad para introducir la cuestión gitana como asunto transversal en los distintas áreas y niveles de la Administración (Bereményi y Mirga, 2012), y para desarrollar medidas adicionales en un momento de constricción del gasto público y de aumento general de la demanda, ha concluido en una apuesta blanda por las políticas focalizadas. Resulta difícil dimensionar estas medidas y sistematizar su alcance e impacto, pero algunos elementos apoyan esta conclusión. En el plano económico, el presupuesto del Programa de Desarrollo Gitano se ha reducido drásticamente de 7,2 millones de euros en 2008 a 1,7 en 2016, con los que se financian 69 proyectos de intervención social integral con las comunidades gitanas más desfavorecidas. Si bien esta pérdida se ha compensado con los presupuestos de las comunidades y entidades locales y, sobre todo, por el recurso a los Fondos Sociales Europeos. Aun así, este montante, cerca de 8,4 millones adicionales en 2016, supone poco menos de los 8,6 millones de presupuesto que el Programa de Desarrollo Gitano tenía por sí solo en el año 2000, por ejemplo3. En perspectiva longitudinal, el impulso de la acción a nivel autonómico y los recursos europeos no parecen haber supuesto un aumento sustancial de los recursos económicos disponibles para gestionar e implementar medidas desde las Administraciones Públicas. En un periodo de fuerte aumento de las necesidades sociales entre la minoría, este estancamiento debe leerse en términos de retroceso. Por otro lado, cabe mencionar que un volumen similar de recursos $(8,3$ millones procedentes de la recaudación del IRPF) se destinan a subvencionar programas de entidades del tercer sector que, al menos tomando como referencia la dimensión económica, reciben un nivel de responsabilidad en la acción inclusiva para con la minoría equiparable al ejercido por el resto de los actores públicos.

Los datos disponibles tampoco permiten sopesar la cobertura de este tipo de medidas. Se ha estimado que en 2016 en torno a 25.027 personas gitanas se han beneficiado de las 115 medidas específicas implementadas a nivel autonómico (financiadas con recursos propios de las autonomías y el Fondo Social Europeo) ${ }^{4}$, a las que habría que sumar las 88.174 personas beneficiarias de los proyectos del

3 Memoria del PDG 2016 e Informe de progreso 2017 de la Estrategia Nacional para la Inclusión Social de la Población Gitana 20122020 (MSCBS). Navarra y País Vasco no reciben financiación por parte del Programa de Desarrollo Gitano, pero sí constan sus aportaciones propias en la memoria económica de la estrategia.

4 Datos del Informe de Seguimiento del Plan Operativo 20142016 (MSCBS).
Programa de Desarrollo Gitano (cofinanciados por los distintos niveles de la Administración). Estas cifras, no obstante, podrían ser menores, puesto que en el cómputo se incluye en algunos casos a los individuos potencialmente atendibles por los proyectos. A ello habría que añadir la divergencia de esfuerzos entre comunidades autónomas; así, por ejemplo, más de la mitad de los proyectos del Programa de Desarrollo Gitano se ejecutan en Andalucía (34,7\%) y Cataluña $(18,8 \%)$, donde se concentra buena parte de la población gitana. Sin embargo, en otros territorios donde también hay un volumen considerable estas medidas específicas están poco desarrolladas.

Con todo, parece vislumbrarse que el grueso del trabajo por la inclusión de la población gitana se ha de dirimir sobre todo en la acción de los modelos de inclusión autonómicos dirigidos al conjunto de la población, incluso donde más medidas focalizadas se impulsan, puesto que sigue existiendo un gran desajuste entre población gitana, necesidades y apoyos.

\section{Algunos límites y retos en la acción inclusiva con la población gitana más desfavorecida}

Las políticas y medidas de inclusión social se han establecido de un tiempo a esta parte como las principales herramientas para reducir las tasas de pobreza y de exclusión social, así como para alcanzar mayores cotas de cohesión y justicia social en nuestras sociedades. Sin embargo, tal y como se articula, el enfoque inclusivo tendría una limitada capacidad para incidir sobre los factores sistémicos que generan las situaciones de desigualdad, exclusión y marginalidad social, tanto porque las transformaciones que promueve, antes que interpelar a la sociedad en su conjunto están focalizadas sobre la situación de desventaja de determinadas categorías y grupos sociales (Stewart 2000), como también porque procuran la igualdad de oportunidades en detrimento de promover y garantizar la igualdad sustantiva o de resultados (Levitas, 2005; 2007). Tal y como ha sido señalado en ocasiones anteriores, las políticas de inclusión apenas se limitarían a llevar al otro lado de la línea divisoria a quienes se encuentran en los márgenes de la sociedad, una meta que sigue siendo compatible con altos niveles de desigualdad y de diferenciación social (Buckmaster y Thomas, 2009; Gray, 2000).

Esta cuestión resulta fundamental en el caso de las minorías más desfavorecidas, cuya vinculación con las posiciones más bajas de la sociedad -aun satisfechas tales necesidades- se mantendría prácticamente inalterada. El análisis de Ladányi y Szelényi (2006) a propósito de la posición que la minoría gitana ha llegado a adoptar en la estructura social ayuda concretar la diferencia entre permanecer en uno y otro margen. La propuesta inclusiva de mínimos podría suponer para el caso de la minoría 
gitana el paso de una posición caracterizada por las escasas posibilidades de movilidad social intergeneracional y la marginalidad en la estructura socioeconómica (underclass) hacia una posición integrada pero igualmente subalterna, desde la que se desarrollan las actividades laborales menos deseables, remuneradas y reconocidas (lowerclass). Desde la perspectiva de Nun (2001), el abandono de la posición de masa marginal y la entrada en cuerpo funcional del sistema productivo.

La situación de vulnerabilidad de la minoría encuentra precisamente explicación en la persistencia de importantes factores exclusógenos de carácter estructural que desencadenan y reproducen las dificultades para escalar posiciones sociales y para mejorar las condiciones de vida de los hogares gitanos. La preeminencia de las relaciones económicas y de clase en el análisis de la problemática gitana ha sido defendida por Calvo (1980:16), quien ha señalado con rotundidad que "las grandes soluciones, por lo tanto, deben ir a largo plazo en el cambio estructural de la sociedad global española”. De por sí, las medidas de inclusión no son incompatibles con tales propósitos. Una versión fuerte de la inclusión social haría hincapié en las causas sistémicas de la exclusión, mientras que el énfasis en el aumento de la participación de los grupos más vulnerables en el sistema productivo (empleo), ha sido identificado con una versión débil de la lucha contra la exclusión social (Perkins, 2010).

La acción inclusiva se desarrolla fundamentalmente a nivel institucional e individual, resultando esta menos eficaz de partida para contrarrestar las situaciones de exclusión. Sin embargo, dentro de sus limitaciones, pueden ser un instrumento adecuado para favorecer la participación social, mejorar el acceso a la protección social y favorecer el acceso al mercado laboral. Esta es la lógica que ha primado en el contexto europeo, y también estatal, y es la base de las demandas y acción de buena parte del movimiento asociativo gitano y de las entidades privadas comprometidas con la situación de la minoría gitana. Pero, incluso en nuestro país, este escenario está fuertemente determinado y comprometido por diversas circunstancias que lo diferencian de nuestro contexto más próximo, introduciendo algunas limitaciones adicionales a la acción inclusiva. Se han señalado como elementos clave la falta de empleo para los sectores de población más desfavorecidos y un mercado secundario/informal igualmente devaluado, el fuerte carácter contributivo de sistema de protección por desempleo, y la carestía de algunos bienes básicos, especialmente la vivienda (Pérez Eránsus, 2016). El caso de la minoría gitana se ve todavía más complejizado si cabe por la discriminación y por la competencia interétnica, y por la marcada multicausalidad de la situación de exclusión de un sector amplio de la minoría.

Una característica excepcional de la situación de la minoría es la mayor incidencia de la exclusión severa. Un 54,4 \% de la población gitana autóctona se encontraría en esta situación según datos de la Encuesta sobre Integración Social y Necesidades Sociales de la Fundación Foessa (2014). Una situación sin parangón con la del resto de la población (para quien esta situación alcanzaba apenas a un 9,5\% del total, cerca de seis veces menos), y que implica, en consecuencia, una acumulación simultánea de dificultades mucho mayor. La exclusión del empleo y de la vivienda alcanza a la inmensa mayoría de la población gitana autóctona, al tiempo que las dificultades vinculadas con la salud recaían en algo más de la mitad de la población y las vinculadas con la educación a cuatro de cada diez individuos gitanos (ver Tabla 1). En conjunto, más de un $45 \%$ de la población gitana encontraría dificultades en más de tres de estas dimensiones a la vez, mientras para el resto de la población apenas ocurre en un $16 \%$ de los casos.

Inevitablemente, plantear itinerarios de inclusión para los individuos y familias gitanas demanda con mayor frecuencia intervenciones integrales, lo que va a poner a prueba no solo la eficacia de las medidas de inclusión dispuestas, sino también la capacidad de los distintos actores comprometidos con la situación de la población gitana de coordinar y aglutinar esfuerzos. A ello hay que añadir que la minoría gitana se va a ver agraviada todavía más por el inconveniente añadido de que ni los procesos de inclusión-exclusión mantienen una vinculación de suma cero (Silver ,2007), ni la intervención sobre algunas de las dimensiones es capaz de generar círculos virtuosos de inclusión, contrariamente a lo que ocurre con los procesos de exclusión que parten del deterioro en algún ámbito -como la ruptura con los vínculo laborales o familiares-y que provocan la concatenación de dificultades en nuevas dimensiones por la pérdida de capacidad de consumo y del capital social (Paugam, 2007).

Esta ha sido, sin embargo, en líneas generales, la lógica desde la que se ha procurado promover la inclusión de los sectores de población más vulnerables, incluso aquellos que, como una parte significativa de la población gitana, se encuentran en situación de exclusión más severa. El acceso al empleo ha sido entendido como un factor catalizador de la incorporación social, tanto para la emancipación de los apoyos institucionales, como para la mejora del bienestar psicosocial. Sin embargo, en las últimas décadas se viene poniendo en cuestión no solo la efectividad, sino también el sentido de las intervenciones vinculadas con la inserción y activación laboral en el ámbito de la inclusión social. La exclusión puede afectar al bienestar individual de maneras que poco o nada tienen que ver con la participación en el mercado laboral (Gray, 2000), al tiempo que el vínculo entre inclusión y empleo está cada vez más debilitado en nuestras sociedades, tal y como muestra la emergencia de fenómenos como el aumento de personas que a pesar de trabajar se encuentran por debajo del umbral de la pobreza. La capacidad del empleo para favorecer la inclusión social implicaría sobre todo que nuestras sociedades fueran capaces 
de generar oportunidades de empleo, especialmente entre los sectores de población más desfavorecidos, y sin embargo en nuestro país el origen social determina con más fuerza las probabilidades de desempeñar empleos temporales y de peor calidad que en otros países de nuestro entorno (Avram y Cantó, 2016).

Tabla 1. Proporción de población gitana afectada por cada una de las dimensiones de la exclusión social

\begin{tabular}{|l|c|}
\hline Dimensiones & $\%$ \\
\hline Empleo & 93,2 \\
\hline Vivienda & 82,4 \\
\hline Salud & 52,7 \\
\hline Educación & 44,7 \\
\hline Consumo & 37,3 \\
\hline Política & 30,1 \\
\hline Conflicto social & 21,3 \\
\hline Aislamiento social & 4,1 \\
\hline
\end{tabular}

Fuente: Elaboración propia a partir de datos de la Encuesta sobre Integración Social y Necesidades Sociales (Foessa, 2014).

Precisamente la situación de buena parte de la minoría es claro reflejo de la lejanía de esta última condición en nuestro país. Todavía hoy una parte amplia de la minoría está muy alejada del empleo. Cerca de un tercio de la población gitana mayor de 16 años nunca ha tenido un contrato laboral (un $31,5 \%)$, casi 20 puntos porcentuales por encima del dato para la población restante. Además, apenas un $23,7 \%$ habría tenido esta vinculación con carácter estable, lo que supone cerca de 2,4 veces menos que entre el resto de población que sí ha podido disfrutar de un contrato fijo (datos de la Encuesta sobre Integración Social y Necesidades Sociales, Foessa, 2014). Incluso en Navarra, donde las tasas de paro han sido tradicionalmente más bajas que en el resto del territorio estatal, la minoría ha gozado de menos oportunidades laborales. En 2011, la tasa de empleo de la población gitana (entre 16 y 64 años) de la Comunidad Foral era de un 33,0\%, casi la mitad que para el conjunto de la población, cuya tasa alcanzaba por aquel entonces un 64,8\% (FSG-Navarra, 2012). $\mathrm{Si}$ atendemos a las situaciones de desempleo, como cabría esperar, también en el caso de la minoría estas se prolongan por mucho más tiempo: un $47,9 \%$ de la minoría se encontraría en situación de desempleo de muy larga duración (más de dos años), de entre las cuales un $21,5 \%$ llevaría buscando empleo más de cuatro años.

La limitada experiencia laboral previa y los bajos niveles de cualificación se encuentran sin duda entre las principales barreras para la participación de la población gitana en el mercado laboral, más si cabe ante la disminución de la oferta del empleo menos cualificado. Pero la trampa de la pobreza y los altos niveles de endeudamiento de los hogares - que ocasiona que los ingresos sean absorbidos por las deudas en vez de mejorar las condiciones de vida- han sido señalados también como importantes obstáculos (Bodewig y Kurekova, 2009), en tanto que desactivan el interés por trabajos que no aportan el rendimiento ni la estabilidad suficiente a los hogares, y que resultan muchas veces penosos.

Habría que considerar en cualquier caso que todavía más de un tercio de la población gitana seguiría desempeñando el comercio ambulante como estrategia económica y laboral principal. Actividad, por otra parte, que ha sido considerada como tabla de salvación de la minoría ante la dificultosa competencia en el mercado laboral ordinario - sobre todo por los puestos más bajos de la escala laboral- con el resto de la población menos cualificada. Ciertamente, ya desde principios de la pasada década se viene constatando el progresivo agotamiento de esta actividad, por el aumento de competencia, el cambio de patrones de consumo, o la dificultosa modernización del mercadillo por los estrechos márgenes de beneficio de las familias comerciantes de un tiempo a esta parte (Mena, 2007; Rodríguez et al., 2011).

Así las cosas, todo ello comprende un importante reto para la inclusión de la minoría. En primer lugar, porque las evidencias indican que el grueso de la población gitana - quizá con más énfasis desde que se han agotado las estrategias económicas y laborales más tradicionales y su conversión de medios de vida hacia medios de subsistencia- necesitan incorporarse con mayor ímpetu al trabajo asalariado o normalizado. Y, en segundo lugar, porque esta demanda se hace además desde una clara posición de desventaja, ya que, la antedicha lejanía del empleo ordinario implica a priori una débil capacidad competitiva, al ser menor el cúmulo de saberes, experiencias y redes en torno al mercado laboral ordinario que puedan facilitar la entrada en él.

Vistas las dificultades para el acceso a las rentas del trabajo, las rentas sociales tienen un claro protagonismo en la protección económica de los hogares gitanos, y especialmente las rentas mínimas autonómicas. En todo ello habría que tener en cuenta que hay dos limitaciones de los sistemas de garantía de ingresos que afectan especialmente a la población gitana. Por un lado, la difícil cobertura de las situaciones de pobreza más severas por las rentas mínimas autonómicas, que en el caso de la minoría alcanza a cerca de un $38 \%$ de los hogares, frente al 6,5\% del resto de la población (Foessa, 2014). Y, por otro, la desprotección económica general de la población gitana por el desigual desarrollo -0 infradesarrollo en algunos casos- de las rentas mínimas autonómicas en algunos territorios.

En este ámbito también existen pocos datos específicos sobre la población gitana, pero se puede prever que en algunos territorios podría estar desprotegida económicamente si se tiene en cuenta la concomitancia de dos fenómenos: la antedicha mayor tasa de pobreza severa en el seno de la comunidad gitana y la menor cobertura y cuantía de las prestaciones de mínimos precisamente 
en algunos territorios donde se concentra históricamente gran parte de la minoría. En el anverso, en muy pocos territorios el desarrollo de la prestación es tal que permite cubrir las situaciones de más desprotección. En Navarra se estima que la renta mínima autonómica (Renta Garantizada) alcanza a algo más del $50 \%$ de los individuos gitanos de la Comunidad 5 , una proporción por encima de la tasa de pobreza severa que se acaba de señalar.

La consecuencia más inmediata de este escenario es el incremento de las privaciones y, entre ellas, de manera muy significativa, como se señaló, la dificultad para hacer frente a los gastos de vivienda. Son conocidos los avatares del mercado inmobiliario que han traído consigo un aumento de las dificultades de los hogares tanto para costear y mantener las residencias habituales como para acceder a ellas. Además, en los últimos años se ha ido produciendo una importante variación en la problemática. Si durante la primera etapa de la crisis las dificultades se vincularon sobre todo con la pérdida de las viviendas ante la imposibilidad de hacer frente a los préstamos hipotecarios, de un tiempo a esta parte ha ido adquiriendo mayor centralidad el aumento del precio de los arrendamientos, y el consecuente aumento de las expulsiones de los inmuebles por el impago de las mensualidades. La concurrencia de esta tendencia con el estancamiento o pérdida de los ingresos de los hogares ha contribuido a la consolidación de las privaciones relacionadas con la vivienda una década después del estallido de la crisis inmobiliaria. La fuerte pérdida de poder adquisitivo de los quintiles más bajos de la escala de ingresos ha hecho más vulnerable si cabe a este sector de la población, y entre ellos, a un buen número de familias gitanas en situación de pobreza. Con frecuencia los sectores de población con menos recursos se ven en la necesidad de poner en juego estrategias como la búsqueda de arrendamientos en zonas donde estos resulten más económicos, lo que muchas veces no resulta inmediato por la creciente competitividad por estos alojamientos de otros grupos poblacionales (jóvenes, población inmigrante). La competencia por la vivienda económica puede acabar por forzar a los grupos más desfavorecidos a acceder a alquileres más altos (consolidando las dificultades económicas), salir del entorno urbano hacia zonas rurales (donde las posibilidades de inserción y los recursos de inclusión son menores), hacinarse con otros núcleos familiares, u ocupar viviendas.

Por otro lado, el aumento de las acciones discriminatorias en el continente europeo ha reavivado el debate sobre estas prácticas como auténticos obstáculos para la inclusión e integración de la población romaní. Recientemente el Parlamento Europeo solicitó a los estados miembros adoptar acciones concretas para erradicar y contrarrestar el antigitanismo (Resolución de 25 octubre de 2017),

${ }^{5}$ Datos del Diagnóstico Social de Navarra del Observatorio de la Realidad Social, 2018. término bajo el cual de un tiempo a esta parte se vienen agrupando todos los actos de marginación, exclusión o trato de inferioridad dirigidos expresa o indirectamente hacia la minoría. Se trata este de un fenómeno persistente y muy enraizado también en nuestra sociedad. La población gitana sigue acaparando la animadversión y el rechazo por parte de un volumen nada despreciable de la población mayoritaria, tal y como ha quedado evidenciado una y otra vez en los análisis realizados al respecto. Así, según datos de la última encuesta sobre percepción de la discriminación en España (CIS, 2016), un $48,6 \%$ de la minoría se había sentido alguna vez discriminada en los doce meses previos a la consulta. Este tipo de actitudes y conductas, según queda recogido también en otras fuentes a nivel europeo (EU-MIDIS II, 2016), se perciben con mayor probabilidad cuando los individuos gitanos tratan de alquilar una vivienda (un $45 \%$ en los cinco años previos), buscar un trabajo (34\%) o, en general, cuando hacen uso de servicios públicos o privados ( $37 \%)$. Estos espacios más propensos a la manifestación de conductas y acciones discriminatorias coinciden con aquellos que se señalaban anteriormente como principales frenos para la construcción de itinerarios de inclusión e incorporación social.

El antigitanismo no solo contribuye a la minusvaloración de la población gitana, sino que también ocasiona la extensión y consolidación de muchas de las dificultades materiales que esta atraviesa y debilita todavía más la condición ciudadana de pleno derecho de muchos de sus miembros. Es en este punto donde antigitanismo e inclusión social concurren, por lo que la vinculación que mantienen entre sí ha comenzado a ser también objeto de gran debate e interés. La cuestión estriba en qué capacidad tienen las políticas de inclusión para erradicar -o reducir - el antigitanismo, y en qué medida las prácticas discriminatorias reducen la eficacia de las medidas dispuestas para contrarrestar la situación de exclusión de la minoría.

De un lado se postula aquella perspectiva que considera que el antigitanismo encuentra su principal justificación en la situación de marginalidad y exclusión de la minoría, al mismo tiempo que contribuiría a reforzar estas circunstancias. Los dispositivos y las políticas de inclusión, en la medida en que ayudan a erradicar las situaciones de desventaja antedichas, contribuirían progresivamente a erradicar el antigitanismo. Esta ha sido la perspectiva generalmente adoptada por las instituciones europeas, quienes han visto en ello un argumento más para justificar el desarrollo de medidas a favor de las comunidades romaníes. En el lado anverso se posicionan quienes sostienen que el antigitanismo tiene una naturaleza sistémica, tanto en sus orígenes como en sus efectos. El antigitanismo se manifiesta con frecuencia a través de conductas individuales, pero afecta a las personas romaníes independientemente de si alguna vez se han enfrentado individualmente 


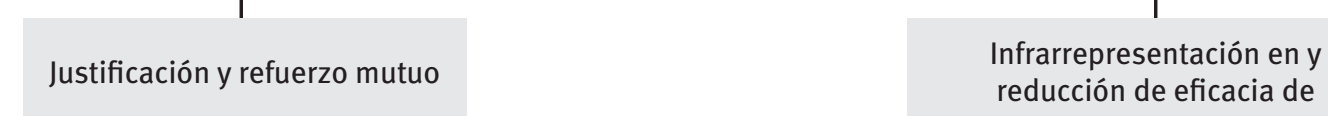

\section{Políticas de inclusión}

Fuente: Elaboración propia.

a algún acto específico de discriminación o trato injusto (Albert et al., 2016). Este influye en el impacto de las políticas de inclusión reduciendo su eficacia cuando la población gitana es rechazada por su pertenencia étnica al tratar de acceder a puestos de trabajo y alquileres, pero también por la infrarrepresentación de la minoría en las medidas que tratan de compensar y reducir las desigualdades, o la desatención de los factores estructurales que inciden en su exclusión (ver Figura 1).

\section{La acción inclusiva con la minoría gitana en la Comunidad Foral de Navarra}

Según datos del Mapa sobre vivienda y comunidad gitana en España (2015) se estima que la población gitana en Navarra es de poco más de 7.550 personas, lo que supone en torno a un 1,2\% de la población de la Comunidad Foral y un 1,5\% aproximadamente de la población gitana estatal. Según las mismas estimaciones, solo en Andalucía y Murcia -donde la minoría supera el $2 \%$ de la población- la comunidad gitana tendría un peso demográfico proporcionalmente mayor.

En cualquier caso, no es solo esta considerable dimensión -en términos relativos- la que ha motivado la atención específica sobre la minoría, sino que, como en otras regiones, ha sido la profunda distancia con respecto a la población mayoritaria la que ha dirigido el foco hacia ella. Distancia que además es especialmente visible en un territorio donde muchos de los indicadores socioeconómicos se han mantenido por debajo de la media estatal, pero que no han alcanzado por igual a toda la población. Así, por ejemplo, resulta categórico que mientras la tasa de empleo para el conjunto de la población en 2011 era más baja en la Comunidad
Foral que en el país (13,9 y 20,9 respectivamente), en cambio, la tasa de desempleo de la minoría se mostraba mucho más elevada en el territorio navarro. Dicha tasa en el caso de la población gitana ascendía hasta un vertiginoso 50,2 \%, 13,8 puntos porcentuales por encima del dato estatal (36,4\%).

Será precisamente en 2011 cuando se promulgue el I Plan Integral de Atención a la Población Gitana de Navarra (2011-2014). La Comunidad Foral asumía de este modo su responsabilidad en la consecución de los objetivos que a nivel estatal se establecieron un año antes en el Plan de Acción para el Desarrollo de la Población Gitana 2010-2012. No ha sido hasta el presente año cuando se ha dado un nuevo impulso a la cuestión gitana con el fomento de una nueva Estrategia para el desarrollo de la población gitana de Navarra (2019-2022).

Como es característico en el ámbito de las políticas de inclusión, en el mapa de recursos están involucradas una gran multiplicidad de agentes sociales. En líneas generales, como en otros muchos territorios, los programas dirigidos expresamente hacia la población gitana están desarrollados principalmente por entidades del tercer sector de acción social, así como por el asociacionismo y movimiento gitano, aunque en su mayoría cuentan con apoyo económico por parte de la Administración Pública a través de convocatorias o subvenciones (además de otras fuentes propias o terceras). El tejido asociativo gitano en Navarra, como ha ocurrido en otros lugares y en otros ámbitos (discapacidad, juventud, etc.), ha ido profesionalizándose y aumentando su interés por el diseño y gestión de programas y servicios, especialmente en el ámbito educativo.

Las entidades privadas han liderado el desarrollo de programas socioeducativos en distintos centros 
de educación infantil y primaria (CEIP) y en diversos municipios, donde ejercen una importante labor de apoyo escolar y de promoción de la convivencia en los centros. También este es el caso -ya en el ámbito laboral- del programa Acceder promovido y desarrollado por la Fundación Secretariado Gitano (FSG), cuya metodología de intervención promueve itinerarios de acompañamiento sociolaboral individualizados. Según datos de la memoria del programa, en 2017, 581 personas fueron atendidas (el $80 \%$ gitanas) y 122 personas accedieron a un empleo.

Especial mención entre los dispositivos de inclusión dirigidos expresamente hacia la minoría requiere el programa de promoción de la salud de minorías étnicas, iniciado en 1987 y pionero en la atención expresa a la población gitana en este ámbito. Su financiación corresponde al Instituto de Salud Pública y Laboral (ISPL) del Gobierno de Navarra, que se encarga también de su coordinación. A través del programa, una decena de agentes comunitarias gitanas - contratadas desde las entidades gitanas del territorio colaboradoras- brindan información, asesoramiento y acompañamiento en materia de salud a las familias e individuos gitanos que así lo requieran, al tiempo que trabajan con los equipos profesionales del sistema de salud para mejorar la intervención y comunicación con la comunidad gitana.

En otro plano se ubican aquellos dispositivos y recursos de inclusión dirigidos al conjunto de la población pero que tienen un especial impacto en la atención de la minoría gitana, bien porque hay un importante volumen de población gitana participando en ellos debido a su situación de desventaja, bien porque la ejecución y gestión de algunos de estos dispositivos recae sobre entidades y asociaciones que trabajan con población gitana, canalizando el acceso a los programas de aquel sector de la minoría que cumpla los requisitos necesarios. Si el desarrollo de la atención específica a la minoría va a resultar en buena medida de la capacidad de acción de las entidades comprometidas con la inclusión de la minoría, en cambio, la atención desde los recursos generalistas se ve mediada por el nivel de progreso y consolidación de las políticas de inclusión en el territorio.

Precisamente la experiencia en el caso navarro ha sido muy notoria en este aspecto. Se trata de uno de los territorios -en comparativa estatal-donde más avances se han realizado en el reconocimiento y desarrollo de prestaciones económicas y programas de servicios sociales garantizados. $Y$ aunque durante el periodo de crisis este progresivo desarrollo no ha mantenido la misma intensidad, produciéndose algunos retrocesos, en la Comunidad Foral se ha mantenido constante la voluntad por concitar los esfuerzos de distintos actores para favorecer la estabilización de los dispositivos y recursos dispuestos en el territorio en materia de incorporación social, laboral y residencial.
Un primer hito definitorio en el desarrollo del modelo de inclusión lo supuso el I Plan de Lucha contra la Exclusión Social en Navarra (PLES) de 1998, una elaboración que se adelantó a sus análogas en otras comunidades autónomas y que no solo definió la exclusión como un fenómeno estructural, sino que también reconocía que la lucha contra esta requiere tanto una respuesta coordinada entre distintos ámbitos y áreas de acción (educación, salud, vivienda, etc.), como involucrar a un amplio número de actores públicos, a instituciones de acción social y al tejido social navarro.

Buena parte del modelo de inclusión de la Comunidad Foral se ha sustentado sobre la premisa de que puede ofertarse empleo normalizado -con distinto nivel de protección- a los sectores de población más excluidos, al tiempo que, mediante el acompañamiento social, se pueden mejorar las posibilidades de acceso e incorporación al mercado de trabajo ordinario. Este es el trasfondo sobre el que se despliegan algunos dispositivos más destacados que hoy continúan vigentes. En la medida que la población gitana ha estado sobrerrepresentada en el espacio de la exclusión, su participación en muchos de estos dispositivos sigue siendo trascendental para favorecer sus itinerarios de inclusión e incorporación social.

En primer lugar, el Programa de Empleo Social Protegido ofrece contratos laborales (de 6 a 12 meses de duración) a personas en situación de exclusión social. Son los ayuntamientos navarros o entidades sin ánimo de lucro quienes proyectan los "tajos" y materializan las contrataciones. Durante el tiempo de estancia en el programa, profesionales del ámbito social realizan un seguimiento personalizado y promueven la adquisición de nuevas competencias laborales. En el año 2017, el $20 \%$ de las personas contratadas en el programa pertenecían a la minoría gitana (153 en total). También los centros de inserción sociolaboral implican un fuerte componente de acompañamiento social individualizado, pero en este caso el contrato de trabajo (de entre 6 y 36 meses de duración) se lleva a cabo en empresas sociales promovidas por entidades sociales que compiten en el mercado ordinario. En Navarra existen en la actualidad 11 centros de inserción sociolaboral. La empresa de inserción Nabut (promovida por la Fundación Secretariado Gitano) desde el año 2003 presta servicios de limpieza, lavandería industrial y venta online de material de oficina, y a lo largo del año 2017 mantuvo 50 contrataciones a población gitana.

Por su parte, los equipos de incorporación sociolaboral refuerzan la atención primaria del sistema de servicios sociales especializándose en el desarrollo de itinerarios individualizados y en el acompañamiento social para fomentar el acceso al empleo normalizado o protegido, apoyar la búsqueda activa de empleo, y la mejora de competencias sociolaborales. Desde estos equipos de incorporación sociolaboral se realizan además labores de intermediación con empresas para 
favorecer el acceso al mercado laboral, lo que supone una clara diferencia con respecto a los centros de inserción sociolaboral y el programa de empleo social protegido, dos recursos muy potentes en la medida en que materializan un contrato laboral desde el inicio de la intervención. En 2016, un $4 \%$ de las personas participantes en los equipos de incorporación sociolaboral formaban parte de la población gitana (69 en total), y apenas un 2,5\% (44 personas) en $2017^{6}$. La proximidad de este recurso con el método de trabajo del programa Acceder y el amplio volumen de población atendido en este explicaría en parte la menor presencia de la minoría en este dispositivo.

Fuera del ámbito laboral, la participación en el Programa de Vivienda de Alquiler e Integración Social conlleva una reducción en el precio de la vivienda durante los cuatro años que dura la estancia en el programa, al tiempo que se realiza un seguimiento de las familias en el proceso de inclusión y acomodación al entorno. Las entidades que participan en el programa gestionan alrededor de 180 actuaciones de acompañamiento profesional, con una media de diez nuevas entradas al programa por entidad al año. La principal vía de acceso al programa VAIS para la población gitana se canaliza a través de las dos entidades de atención específica a la minoría que colaboran en la gestión del mismo (Fundación Secretariado Gitano y Asociación La Majarí).
Por su parte, en el ámbito educativo, en Navarra existe una convocatoria anual que tiene como objetivo la concesión de ayudas para la contratación de una figura de promoción escolar o mediación sociocultural en centros públicos de enseñanza. Dicha figura fomenta la inclusión socioeducativa del alumnado a través del trabajo en red con las instituciones de la zona implicadas en la inclusión social y educativa, y de la implementación de estrategias en los centros para favorecer la participación de las familias y del alumnado, fomentar la convivencia en los centros, dar apoyo al alumnado en situación de conflicto o riesgo, etc. Desde hace cuatro años se ha venido enfocado el recurso hacia la atención del alumnado gitano en un centro concreto de la comunidad. Con el apoyo del tejido asociativo gitano (Federación Gaz Kaló) se han logrado alcanzar resultados positivos en la reducción el absentismo y en la mejora de la relación entre las familias y la institución.

Con todo, el papel del asociacionismo gitano y de las entidades privadas especialmente comprometidas con la inclusión de la minoría no solo ha sido determinante para la atención específica de la minoría en la Comunidad Foral, sino que, debido al importante papel que las entidades privadas han tenido en la gestión de algunos de los recursos más importantes, la participación de la minoría en los recursos generalistas se ha canalizado y "asegurado"

Tabla 2. Principales recursos de inclusión para la comunidad gitana en Navarra

\begin{tabular}{|c|c|c|}
\hline Ámbito & $\begin{array}{l}\text { Dirigidos al conjunto de la población, con especial impacto en } \\
\text { la minoría gitana }\end{array}$ & Dirigidos a la población gitana en específico \\
\hline Educación & $\begin{array}{l}\text { Ayudas para la contratación de la figura de promotor escolar } \\
\text { o mediador sociocultural que intervenga en proyectos de } \\
\text { inclusión socioeducativa en centros públicos (Federación Gaz } \\
\text { Kaló, Fundación Secretariado Gitano). }\end{array}$ & $\begin{array}{l}\text { Programas de normalización e intervención } \\
\text { socioeducativa de la Fundación Secretariado Gitano } \\
\text { en distintos Centros de Educación Infantil y Primaria; } \\
\text { Programa Promociona de apoyo y orientación } \\
\text { educativa de la Fundación Secretariado Gitano; } \\
\text { programas socioeducativos de la Federación Gaz } \\
\text { Kaló, asociaciones La Majarí y La Romaní en distintos } \\
\text { municipios. }\end{array}$ \\
\hline Empleo & $\begin{array}{l}\text { Centros de Inserción Sociolaboral (Fundación Secretariado } \\
\text { Gitano); } \\
\text { Empleo Social Protegido; } \\
\text { Equipos de Incorporación Sociolaboral; }\end{array}$ & $\begin{array}{l}\text { Programa Acceder de la Fundación Secretariado } \\
\text { Gitano de incorporación sociolaboral. }\end{array}$ \\
\hline Vivienda & $\begin{array}{l}\text { Viviendas de Alquiler e Integración Social (Fundación } \\
\text { Secretariado Gitano, La Majarî); } \\
\text { proyecto de intervención comunitaria socioresidencial en } \\
\text { bloques de vivienda de alquiler de la sociedad pública } \\
\text { Nasuvinsa (Ayuntamiento de Berriozar, Fundación } \\
\text { Secretariado Gitano, Asociación La Majarí, Nasuvinsa, } \\
\text { mancomunidad de servicios sociales, etc.). }\end{array}$ & \\
\hline Salud & & $\begin{array}{l}\text { Programa de promoción de la salud con la comunidad } \\
\text { gitana (Fundación Gaz Kaló y Asociación La Majarî). }\end{array}$ \\
\hline Discriminación & $\begin{array}{l}\text { Servicio de asistencia a víctimas de discriminación por el } \\
\text { origen racial o étnico (Fundación Secretariado Gitano); } \\
\text { Oficina para la igualdad de trata y la no discriminación por } \\
\text { motivos étnicos (SOS Racismo). }\end{array}$ & \\
\hline
\end{tabular}

Fuente: Elaboración propia. 
por esta vía. Lo central es que, además, la presencia de las entidades en la gestión de sistema incorpora algunos valores añadidos. Por un lado, cumple el propósito de incorporar a la minoría - o en este caso al tejido asociativo gitano- en la atención de sus propias necesidades. Por otro $-y$ necesariamente-, debido al contacto continuo con la comunidad y las familias, los equipos técnicos han podido adquirir un conocimiento profundo de las situaciones de los hogares y, en su caso, complementar sus itinerarios con otras actuaciones, programas formativos, labores de búsqueda de empleo, mediación en situaciones conflictivas, etc. Además, ante la compleja tarea de determinar quiénes acceden a los limitados recursos, este profundo conocimiento ha podido favorecer la asignación de los recursos más intensos (CIS, VAIS, etc.) a aquellos casos en los que la participación podría suponer un impulso definitivo a los procesos de inclusión.

\section{Hacia el análisis del escenario inclusivo en el caso de la minoría}

A la hora de analizar los obstáculos de la acción inclusiva en el caso de la población gitana, habría que tener en cuenta al menos dos dimensiones de análisis. Por un lado, aquellas limitaciones propias de los recursos y medidas, comunes al conjunto de la población y que, por tanto, aunque involucran a la minoría, la trascienden. Y, por otro lado, aquellas cuestiones que circundan la particular situación de la minoría excluida y que, en el peor de los casos, amplifican estas limitaciones. Como ha sido señalado con anterioridad, el caso de la población gitana ilustra con claridad las limitaciones y debilidades de las políticas de inclusión en nuestro país (Rodríguez, 2018). La hipótesis de partida es que, además, sus ineficiencias se manifiestan con mayor rotundidad en el caso de la minoría más vulnerable, viéndose reducido notablemente su impacto. El escaso rendimiento que buena parte de la minoría parece obtener de este tipo de apoyos respondería así fundamentalmente a esta cuestión, y no a otros factores vinculados con las características intrínsecas a las comunidades gitanas a las que se suele recurrir con frecuencia.

Como se ha señalado, los mayores índices de exclusión y pobreza severa son uno de los principales determinantes, más todavía si se tiene en consideración la dificultosa tarea de revertir estos procesos cuando son de largo recorrido, y por los que las familias y miembros de la minoría, desde luego, no transitan indemnes. A esto habría que añadir que aquellos escenarios que condicionan con más fuerza el escenario de inclusión en nuestro país -el mercado laboral y de la vivienda - son precisamente espacios de los que la minoría se ha visto especialmente excluida. Huelga decir que, sin embargo, ni esta situación es exclusiva de la población gitana, ni es la de toda la minoría, por lo que la diversidad de situaciones-problema en su seno es otra cuestión no siempre suficientemente tenida en cuenta.
Sí resulta particular en este caso - también en el de otras minoría étnicas y culturales - el influjo de la discriminación o antigitanismo. La pertenencia étnico-cultural suele estar en la base de fenómenos como el acceso diferencial al mercado de la vivienda, al sistema educativo, o al empleo (Giménez, 1994, citado en Malgesini y Giménez, 2000), y aunque probar los hechos discriminatorios no resulta sencillo, la experiencia y testimonio de la población gitana deja poco espacio a la duda sobre su existencia, tal y como se desprende de los estudios sobre discriminación y población gitana disponibles (Fundación Secretariado Gitano, 2018).

Con todo, para este trabajo se han tomado en consideración como políticas de inclusión aquellas medidas que tratan de facilitar la salida de las situaciones de exclusión mediante una prestación económica/material, la mejora de la formación o capacitación laboral, o a través del acompañamiento profesional. El análisis de la experiencia a través de los relatos de vida de la propia población gitana muestra cómo se imbrican esos factores generando nudos en sus itinerarios de inclusión. Para este estudio se han tomado como referencia los relatos de veinticinco familias gitanas vulnerables perceptoras de ingresos mínimos y que participan o han participado en alguno de los dispositivos al uso de la Comunidad Foral. De este modo, no solo se incorpora la valoración que los propios individuos hacen de los recursos y de su impacto en sus condiciones de vida, sino que también, desde su experiencia, pueden identificar algunas de las disfuncionalidades y potencialidades de los recursos.

Además de enunciar algunos de estos nudos, en las líneas siguientes se trata de esbozar algunas claves que contribuirían a mejorar la capacidad de las medidas de inclusión para avanzar en su propósito.

\section{Algunas oportunidades para avanzar y favorecer la inclusión de la minoría más vulnerable}

La exigencia de este tipo de medidas inclusivas para la población gitana comienza como resultado de lo que ha sido definido como "desmercantilización forzosa" (Laparra y Pérez Eransus, 2010) y que, en el caso de la minoría, dada su exclusión del empleo, resulta especialmente visible. Pero también resulta de la interrupción del creciente proceso de asalarización - principalmente en sectores manuales y de servicios- que se había iniciado en las dos décadas anteriores a la crisis, y del agotamiento de algunos espacios laborales que hasta hace poco procuraban situaciones económicas relativamente estables a las familias gitanas, como la venta ambulante, que durante las pasadas décadas favoreció la incorporación a la Seguridad Social de muchos comerciantes autónomos. 
7.1. El refuerzo y flexibilización del sistema de garantía de ingresos tendría un gran impacto en la protección económica de la minoría

Cuatrocientos veintiséis euros, pues bueno, una persona sola puede tirar, pero cinco personas cuando son de edad escolar, que tienes que comprarles la ropa, tienes que comprarles el calzado, les tienes que comprar cuadernos, bolígrafos, almuerzos todos los días y las meriendas, pues... no, ¡no llegas! (Constantino, 46 años)

La consecuencia más inmediata es que la población gitana se ha visto particularmente perjudicada por la impronta contributiva del sistema de protección social en nuestro país. La preeminencia de la protección asistencial ha resultado la otra cara de la moneda del celebrado acceso al sistema de protección universal por parte de la minoría, e incide con fuerza en el significativo sector de esta que presenta trayectorias laborales cortas $\mathrm{y} / 0$ caracterizadas por el subempleo y la subocupación. Especialmente delicada es esta situación en los hogares con menores. El escaso desarrollo de las políticas de protección a la infancia ha impedido neutralizar el aumento de las tasas de pobreza infantil en nuestro país. En virtud de las altas tasas de natalidad entre la población gitana, y de la débil situación económica de muchas de los hogares, estos han sido especialmente vulnerables ante este fenómeno. Y aunque un importante número de hogares gitanos se benefician de las prestaciones por hijo a cargo del Instituto Nacional de la Seguridad Social, apenas alcanzan a aliviar momentáneamente las maltrechas economías familiares.

Las dificultades económicas que derivan de la falta de rentas de empleo se abordan en el caso de la minoría con especial protagonismo desde las rentas mínimas autonómicas, por lo que su desarrollo y cobertura va a ser trascendental más si cabe para ella. Ya se señaló que en el caso de Navarra la cobertura de la prestación de renta mínima alcanza a casi la mitad de la población gitana de la comunidad, lo que ha de ser valorado en términos positivos por la capacidad demostrada por la prestación para proteger al sector de la población gitana con mayores dificultades. En Navarra la renta mínima ejerce una importante función en materia de protección económica, pero también, tal y como ha quedado recogido en estudios previos, muestra algunas limitaciones tanto por el contexto en el que se percibe -como se ha señalado en ocasiones, en algunos territorios donde el coste de la vida es más alto, ser pobre sale más caro- como por la complejidad de las situaciones familiares (ver, por ejemplo, Pérez Eransus y Martínez Virto, 2015; Lasheras et al., 2017).

La chatarra no es que salga rentable, pero por lo menos si te ha traído diez euros... Uno no tiene que esperar a cobrar [la renta mínima], es que si no, qué comes todo ese mes... claro que lo pasamos todos mal, porque esperas a cobrar el mes y cuando cobras tienes un montón de pagos y lo poco que te queda... (Marta, 39 años)

Cabe recordar en este punto que en el caso de la minoría ha sido tradicionalmente habitual el uso estratégico de las prestaciones sociales junto con otras actividades económicas (compraventa, comercio ambulante, recogida de residuos, etc.) para sortear la baja cuantía de las prestaciones y los huecos entre periodos de percepción. Sin embargo, el aumento del control sobre estas actividades, el auge del sector de recogida de residuos y el reciclaje, y el aumento de la competencia con otros sectores de población hacen que el aporte estas alternativas no compense, ya que en algunos casos las sanciones administrativas ahondan todavía más precarias economías domésticas.

Con todo, la flexibilización de algunos requisitos de acceso a las prestaciones económicas para quienes desarrollan empleos de exclusión es un debate necesario para abordar para luchar contra la pobreza en el país, y en particular la de sectores, como el gitano, donde estas prácticas tienen un peso mayor como resultado de mencionada desmercantilización forzosa. También la mejora en la protección económica de las familias con cargas para afrontar la pobreza infantil y prevenir sus consecuencias en el futuro repercutiría positivamente en muchos hogares gitanos. En suma, avanzar hacia un sistema de garantías de ingresos mínimos adecuado se postula como un elemento clave indudablemente también para el caso de la minoría gitana.

En cualquier caso, la vinculación entre protección económica y la minoría no es unívoca. Muchas familias gitanas disponen de las capacidades suficientes para mantener sus hogares de forma autónoma, y precisan solamente de protección económica para sortear las posibles contingencias que puedan surgir y, en su caso, apoyos para mantener esta independencia. Existe también un importante volumen de casos entre la minoría que, con los apoyos adecuados, puede aumentar sus opciones para emanciparse de las prestaciones asistenciales, al tiempo que todo apunta que para algunos hogares se requiere ante todo protección económica, y el establecimiento de objetivos de inclusión a largo plazo con perspectiva intergeneracional.

\subsection{Apoyar el mantenimiento de actividades tradicionales es una medida preventiva, pero también estratégica}

Se ha sostenido en ocasiones anteriores que las oportunidades que ofrecen la economía informal o las actividades marginales pueden llegar a ser más estables y fructíferas que sus antagónicas. Incluso que estas actividades pueden aportar algunos rendimientos -más allá de los económicos-que las hacen una opción más atractiva: preservan 
hábitos y habilidades, desarrollan capacidades y redes y, en última instancia, aumentan las posibilidades de incorporarse en el trabajo formal (Marshall, 2005: 201-202). Esta perspectiva invita a superar la visión fraudulenta de estas estrategias y avanzar hacia lógicas que las incorporen como un instrumento más para la mejora de las condiciones de los hogares.

Entre los relatos recogidos para este estudio hay experiencias de tránsito desde el mercadillo a puestos sedentarios cuando se ha tenido ocasión, o en las que se hace válida la experiencia en el mercadeo para entrar a trabajar en el sector textil, lo que reafirma lo antedicho. La población gitana no es una tabula rasa de habilidades y competencias laborales en definitiva. Ya desde la propia comunidad se ha sostenido que la Administración Pública debe apoyar la inserción laboral de la minoría aprovechando las competencias y habilidades aprendidas en las actividades que muchos de sus miembros han venido desarrollando hasta ahora, en tanto coinciden, en ocasiones, con las demandadas del actual mercado laboral (Vargas, 2004).

Yo en mi caso hago trabajo para alimentarme, sin beneficio ninguno, nada más que empleando trescientos euros [venta ambulante] y convirtiéndolos en seiscientos, otras veces en quinientos... Pero lo que uso es el tiempo. Si con trescientos euros ocupo un mes, pues empleándolo ocupo dos meses. (Daniel, 35 años)

De igual modo, de un tiempo a esta parte se ha producido una fuerte conversión de estas estrategias económicas en recursos de mera supervivencia. Parece evidente que, en casos como el anterior, con apoyo institucional se podría ayudar a mantener la actividad con objeto de prevenir que se desencadenen procesos de exclusión más agudos. Hacer flexibles los ingresos de la venta ambulante con las rentas mínimas, e incluso estimular su desarrollo con ayudas al autoempleo, apoyo para la creación de cooperativas sociales o la mejora de la cualificación y formación de los vendedores y vendedoras parecen estrategias plausibles.

\subsection{Impulsar el desarrollo de recursos sociolaborales e incorporar nuevos enfoques abriría oportunidades de inserción laboral para la minoría}

Como se señalaba anteriormente, para un nutrido sector de la minoría gitana los recursos de incorporación sociolaboral constituyen la principal baza para emanciparse de las rentas mínimas. Como también se resaltaba, el retorno al mercado laboral ha tenido un especial protagonismo en el ámbito de la inclusión y, sin embargo, el mapa de recursos en Navarra presenta algunas limitaciones. Entre ellas se pueden destacar, en primer lugar, que sel nivel de cobertura de los dispositivos de incorporación sociolaboral continúa siendo bajo. Recursos como el Programa de Empleo Social Protegido, el CIS o el
Programa de Equipos de Incorporación Sociolaboral apenas alcanzan a un pequeño sector de los perceptores de rentas mínimas (un $12,2 \%$ en 2016), si bien es cierto que hay una representación notable de la población gitana en estos. En segundo lugar, este tipo de recursos, concebidos como herramientas de transición hacia el empleo normalizado, de un tiempo a esta parte se han reconvertido en recursos de protección temporales que favorecen el acceso estratégico al sistema de protección social, lo que reduce su potencial inclusivo:

Pues la verdad es que a veces no quiero pensar mucho porque al final uno acaba mal, pero mis expectativas después de este trabajo [ESP], por lo que veo en el panorama, están muy mal. [...] Ocho meses [de contrato] luego pues bueno, aportas paro, y bueno, te da un respiro. (Mariano, 28 años)

$\mathrm{Y}$, finalmente, en tercer lugar, el mapa de recursos de incorporación sociolaboral necesita extenderse no solo para atender a un volumen de población mayor, sino también para adecuarse a una mayor diversidad de perfiles-situación. Los centros de inserción sociolaboral y el Programa de Empleo Social Protegido pueden considerarse recursos de protección intermedios que han de complementarse con recursos de carácter ocupacional y otras fórmulas que apoyen la contratación de la población más cualificada en situación de riesgo. Algo parecido ocurre entre los recursos formativos de los servicios de empleo, que tienen una importante labor por delante para adecuarse a los niveles de preparación previa de las personas más alejadas del empleo y vincular a estas con nichos de trabajo locales.

Precisamente en el marco europeo se ha sostenido que para promover la entrada al mercado de trabajo de la población gitana se precisa acometer reformas en los servicios públicos de empleo para que puedan llegar a aportar una respuesta más individualizada y orientada a quienes tienen mayores dificultades para acceder al empleo. La integración de servicios (de empleo y sociales) para dar una respuesta integral acorde con la multidimensionalidad de la exclusión de la minoría es una de las demandas en este sentido, como también el desarrollo de acciones coordinadas con otros agentes para desarrollar servicios individualizados e intensivos (Bodewig y Kurekova, 2009). Hay además un creciente reconocimiento de que las entidades sociales comprometidas con la minoría y el propio tejido asociativo gitano quienes disponen de los conocimientos, herramientas y el vínculo con las comunidades locales necesarios para desempeñar esa función con garantías, por lo que deberían ser un actor central en ello, tal y como muestra la experiencia española y navarra. 
7.4. El desarrollo de itinerarios prolongados y estables es indispensable para provocar transformaciones, especialmente en el caso de las mujeres gitanas

Con todo, la construcción de itinerarios que resulten cualificantes y acerquen al empleo normalizado supone uno de los principales retos de los dispositivos de inserción laboral, en tanto los nichos de empleo menos cualificados ofrecen en la actualidad pocas y disputadas oportunidades. Todo apunta a que el logro de estos objetivos requiere procesos de capacitación más prolongados, intensos, complejos e incompatibles con lógicas busquen precipitar una pronta salida de las prestaciones de ingresos mínimos. Emprender avances hacia lógicas de doble derecho (derecho a la protección económica, por un lado, y a la inclusión por otro) se postula como condición ineludible para favorecer la inclusión de aquel sector que se encuentra más alejado del empleo.

Es que no hay para encontrar unas horas de limpieza o para cuidar niños o esas cosas, que siempre ha habido, jahora no hay! Y si alguien encuentra unas horas de limpieza, la chica es amiga y se lo ha dejado o cosas así... por conocidos. (Lorena, 24 años)

Esto es más visible si cabe en el caso de las mujeres gitanas. La destrucción del empleo manual en el periodo de crisis reforzó la idea de que las mujeres gitanas podrían tener más posibilidades de acceso al mercado en el sector servicios y de cuidados, lo que podría acarrear consigo algunos cambios en las lógicas de funcionamiento de los hogares, tal y como ha venido ocurriendo en las últimas décadas para el resto de la sociedad. Sin embargo, en la medida en que mucho de este empleo se ha dirigido al entorno privado, es previsible que hayan prevalecido en los hogares demandantes lógicas muy selectivas y discriminatorias, minando las opciones de las mujeres gitanas para acceder a estos espacios. Por otro lado, como muestra la cita anterior, este trabajo doméstico resulta habitualmente muy precario, mostrando que no todo el trabajo informal - contrariamente a lo que se podía deducir de lo dicho anteriormente- resulta provechoso.

Este tipo de realidades ejemplifican con claridad que en determinadas circunstancias la protección económica se postula como la mejor de las opciones frente a la inserción laboral en condiciones que pueden ser contraproducentes (precariedad, explotación, dobles jornadas laborales en el caso de mujeres, etc.). Es desde este planteamiento - una vez garantizados unos ingresos mínimos y con el apoyo de medidas de conciliación en los casos que sea necesario- desde el que parece más oportuno trabajar por lograr a medio a medio-largo plazo la mejora de la cualificación laboral que abra oportunidades de inserción laboral en empleos de calidad, de modo que se pueda promover progresivamente y con mayor solidez el papel de las mujeres gitanas como motor de cambio en el seno de la comunidad.

También habría que asumir que -como ocurre también en muchos hogares no gitanos- en ocasiones el acceso al empleo es un objetivo difícil de cumplir por el cúmulo de problemáticas que lastran algunos hogares. Aportar una mayor estabilidad y seguridad económica en estos hogares y trabajar sobre todo en la promoción y apoyo de los menores parece la vía más adecuada para romper el círculo de la pobreza que mantiene a muchos hogares en situación de vulnerabilidad, tal y como ha sido descrito, por ejemplo, por Caselles (2008).

\subsection{El acceso efectivo a la vivienda tiene un potencial inclusivo que debería ubicar estas acciones en una posición preferencial}

En el ámbito de la vivienda, los últimos datos disponibles mostraban que la población gitana de Navarra accede fundamentalmente desde el mercado libre (72,2\% de los casos), y en un volumen menor $(24,3 \%)$ recibía algún tipo de apoyo económico (Ministerio de Sanidad, Servicios Sociales e Igualdad, 2016). Dentro de esta última modalidad, el acceso a promociones de VPO, el alquiler social de viviendas por parte de la administración pública y el programa Vais han ejercido una notable función en la dignificación de las familias que habitaban en las zonas más segregadas y deterioradas de la comunidad y, en general, han favorecido la normalización de las viviendas de un significativo número de familias (Campos 2009; FSG Navarra, 2007). En concreto, el programa Vais, dirigido expresamente a personas en situación de exclusión social que requieren acompañamiento para su integración social en el entorno, ha permitido acceder a una vivienda a sectores de la población gitana que quedaban al margen de otras iniciativas públicas de vivienda, contrarrestando las situaciones residenciales más extremas y favoreciendo el acceso a la vivienda de las familias gitanas jóvenes.

La intensificación de las necesidades vinculadas con la vivienda entre la minoría ha hecho más visible las limitaciones de este tipo de recursos. El programa Vais ha mantenido un nivel de cobertura bajo en comparación con las necesidades de vivienda, e incluso ha tenido problemas de provisión durante el periodo de crisis. En ocasiones, incluso situaciones de emergencia habitacional han podido quedar fuera del programa por la dificultad de cumplir los requisitos de acceso y la incapacidad para asumir las responsabilidades derivadas de la compra o alquiler de una vivienda.

Llevaba dos años apuntada ahí [Vais], y va conforme lista te van llamando. A lo que me tocaba a mí, jno tenía ningún ingreso! Nada. Tenía todo, mi declaración de la renta y todo bien, solo me faltaba el ingreso y nada. (Ángela) 
El análisis de los relatos muestra que todavía en hogares que participan en el programa Vais, a pesar de las reducciones en las rentas que este conlleva, se mantienen muchas dificultades económicas. Un factor clave que explica este hecho continúa siendo la dificultosa inserción laboral que pueda aportar ingresos suficientes en los hogares en conjunción con las antedichas limitaciones de la prestación de renta mínima. De este modo también se entorpece el asentamiento a futuro en las viviendas una vez que finaliza la participación en el programa (y desaparecen las reducciones en el precio del alquiler).

Lo que parece vislumbrarse con claridad es el importante papel que el acceso a la vivienda tiene en los itinerarios de inclusión de las familias. El acceso a las viviendas supone una escalada en la seguridad material y en la estabilización de los hogares mucho más accesible y rápida que la vía del empleo por sí sola, lo que aviva el debate sobre si resulta más oportuno un cambio de paradigma en los canales habituales empleados por las políticas de inclusión. Las medidas vinculadas con el acceso a la vivienda han sido un instrumento que históricamente ha tenido un fuerte impacto en la mejora de las condiciones de vida de la minoría. Aunque con algunas consecuencias indeseadas como la segregación residencial o el aumento de la competencia interétnica en algunas zonas (Río, 2014), lograron reducir los niveles de infravivienda y chabolismo drásticamente en las últimas décadas del pasado siglo. Un nuevo impulso para hacer efectivo el acceso a la vivienda a los sectores más desfavorecidos puede ser determinante de nuevo en las opciones de integración socioeconómica de la minoría, teniendo en cuenta la pérdida de capacidad inclusiva del mercado laboral.

Estamos más tranquilos, tenemos algo bien, agua caliente, antes estábamos calentando ollas para ducharnos. [...] Hemos mejorado, estábamos en una vivienda que no tenía agua caliente y encima con cuatro niños, eso lo primero. [...] El barrio muy bien, no hemos tenido ningún problema. Además, como estamos cerca de donde estábamos antes... (Julia, 36 años)

\subsection{La lucha contra el antigitanismo requiere de medidas que protejan a la minoría en aquellos espacios donde se produce con mayor frecuencia}

Las medidas para combatir la discriminación negativa, como las dispuestas en Navarra para asesorar y asistir jurídicamente a las víctimas (ver Tabla II), son una condición ineludible para promover un trato más igualitario y erradicar estas prácticas tan perniciosas. En paralelo, los recursos de empleo y vivienda de la comunidad examinados no solo se han demostrado útiles a la hora de proteger a los sectores más vulnerables ante la competencia y la falta de oportunidades laborales o de acceso a la vivienda en el mercado privado, sino que, en muchos casos, también han sido recursos que ha permitido eludir actitudes discriminatorias - por ejemplo a la hora de acceder al alquiler privado- por lo que su impulso podría venir justificado también desde esta óptica. Incorporar a los potenciales actores discriminadores (empresas, promotoras de viviendas, etc.) como un actor inclusivo es una práctica costosa pero eficiente. En el ámbito laboral, incentivar económicamente la contratación en empresas privadas ayudaría a aportar experiencias laborales más prolongadas a la población gitana, como también a favorecer la adquisición de habilidades muy vinculadas con las necesidades del mercado laboral (Bodewig y Kurekova, 2009). Se trata en cualquier caso de medidas de discriminación positiva que podrían dirigirse al conjunto de la población y alcanzar por esta vía a la minoría, como muestra la experiencia navarra con otros dispositivos.

\section{A modo de conclusión}

El análisis del desempeño de las políticas de inclusión en el caso de la minoría gitana parece confirmar la hipótesis de que las limitaciones de los dispositivos inciden en mayor grado sobre esta. Incluso en el caso de Navarra, donde se ha dispuesto de un volumen importante de recursos, no han sido suficientes para atender con eficacia la cuestión gitana, lo que hace más perceptible si cabe que el modelo de integración de la minoría en nuestro país necesita lograr avances en todos sus niveles.

No obstante, adoptando las reformas pertinentes las medidas de inclusión podrían llegar a ejercer una importante función en el fomento de la autonomía de la minoría. En las líneas previas se han esbozado algunas posibles reformas para el debate, y que pasan por la mejora de la seguridad y estabilidad material de los hogares (acceso a ingresos suficientes, acceso efectivo a la vivienda, etc.), por aumentar la intensidad y diversidad de los recursos de incorporación sociolaboral, pero también por adoptar un enfoque más comprensivo e indulgente que no penalice a los sectores más desfavorecidos cuando tratan de "buscarse la vida" y maximizar las opciones de sus hogares. Estos progresos no solo serían valederos para el caso de la minoría, sino que ejemplifican con claridad que, cuando se adopta un enfoque sensible a la casuística gitana, los beneficios se extienden más allá de la minoría, ya que se promueve con ello una mejor atención también para al conjunto de la población. Una lógica, por otra parte, que habría que tener en cuenta para mejorar el posicionamiento de la atención de la minoría en la agenda social.

En el caso particular de Navarra se ha emprendido algunos pasos hacia un escenario inclusivo que permita planteamientos como los aquí esbozados. Se ha promovido el doble derecho a la protección económica y a la inclusión (Ley Foral 15/2016), y se están haciendo esfuerzos por garantizar o expandir algunos de los recursos que se han 
señalado como claves en la incorporación de la minoría en el territorio (como el Empleo Social Protegido o el programa Vais). La nueva estrategia de inclusión para la población gitana (2019) contempla además medidas para apoyar al sector de la venta ambulante y para la mejora de la cualificación de la población gitana más joven. En lo sucesivo el modelo de inclusión de Navarra va a continuar siendo un escenario idóneo para seguir acumulando experiencia y evaluando el impacto de las medidas de inclusión en las biografías de la población gitana. 
ALBERT, G. et al. (2016): Antigypsyism-a reference paper, Alliance against Antigypsyism, disponible en: 〈http://antigypsyism.eu/wp-content/ uploads/2017/07/Antigypsyism-referencepaper-16.06.2017.pdf〉.

ARZA, J. y CARRÓN, J. (2015): Comunidad gitana: la persistencia de una discriminación histórica. OBETS, vol. 10, nํㅜ 2, pp. 275-299.

AVRAM, S. y CANTÓ, O. (2016): Labour outcomes and family background: Evidence from the EU during the recession, Ecineq, Society for the Study of Economic Inequality.

BEREMÉNYI, B.Á. y MIRGA, A. (2012): ¿Perdido en la acción? Evaluación de los seis años del Plan Integral del Pueblo Gitano en Cataluña, Barcelona, Federación de Asociaciones Gitanas de Cataluña.

BODEWIG, C. y KUREKOVA, L. (2009): Enhancing the employment chances of Roma, Washington, The World Bank, Knowledge Brief, 52680.

BUCKMASTER, L. y THOMAS, M. (2009): Social inclusion and social citizenship-towards a truly inclusive society, Research Papers, Canberra, Australian Parliamentary Library.

CALVO, T. (1980): “Las minorías étnicas y sus relaciones de clase, raza y etnia”, Documentación social, vol. 41, pp. 9-33.

CAMPOS, B. (2009): “Intervención sociourbanística en el barrio La Merced de Estella (Navarra)", Gitanos: pensamiento y cultura, vol. 47-48, pp. 66-69.

CASELLES, J.F. (2008): “Factores sociales de la exclusión social del pueblo gitano”, en HERNÁNDEZ, M., Exclusión social y desigualdad, Murcia, Universidad de Murcia, pp. 229-252.
DALY, M. y SILVER, H. (2008): "Social exclusion and social capital: a comparison and critique", Theory and Society, vol. 37, no 6, pp. 537-566.

DAMONTI, P. y ARZA, J. (2014): Exclusión en la comunidad gitana: una brecha social que persiste y se agrava, Documentos de Trabajo, Madrid, Foessa.

FUNDACIÓN SECRETARIADO GITANO (2012): Políticas de inclusión social y población gitana en España. El modelo español de inclusión social de la población gitana, Constanta, Fundación Secretariado Gitano.

- (2018): Discriminación y comunidad gitana. Informe anual FSG 2018, Madrid, Fundación Secretariado Gitano.

FUNDACIÓN SECRETARIADO GITANO NAVARRA (2007): Vivienda y comunidad gitana navarra: vivienda deficitaria, infravivienda y chabolismo, Pamplona-Iruña; Fundación Secretariado Gitano.

- (2012): Población gitana de Navarra y empleo, Pamplona, Fundación Secretariado Gitano.

GAMELLA, J.F. (1996): La población gitana en Andalucía: un estudio exploratorio de sus condiciones de vida, Sevilla, Junta de Andalucía.

GIL CALVO, E. (2009): Cambio global y protección social, en BELTRÁN ADELL, F., Modelos sociales europeos, Madrid, Fundación Rafael del Pino, pp. 151-164.

GRAY, J. (2000): “Inclusion: a radical critique”, en ASKONAS, P. y STEWART, A.: Social inclusion: possibilities and tensions, Londres, Macmillan Press, pp. 19-36.

LADÁNYI, J. y SZELÉNYI, I. (2006): Patterns of exclusion: constructing Gypsy ethnicity and the making of an underclass in transitional societies of Europe, New York, Columbia University Press. 
LAPARRA, M. y PÉREZ ERANSUS, B. (2008): “La comunidad gitana: el grupo étnico más excluido en la sociedad española”, Exclusión social en España: un espacio diverso y disperso en intensa transformación, Madrid, Foessa, pp. 405-423.

LAPARRA, M. y PÉREZ ERANSUS, B. (2010): El primer impacto de la crisis en la cohesión social en España, Madrid, Foessa.

LAPARRA, M.; CORERA, C.; GAVIRIA, M. y AGUILAR, M. (1989): El salario social sudado. Los campos de trabajo experimentales del proyecto Búscate la Vida en Navarra, Madrid, Editorial Popular.

LASHERAS, R.; JABAT, E.; D’OLIVEIRA, M. y SÁNCHEZ DE LA YNCERA, I. (2017): "Efectos desintegradores de las políticas de integración: la Renta de Inclusión Social en Navarra", Cuadernos de trabajo social, vol. 30, no 2, pp. 315-327.

LEVITAS, R. (2005): The inclusive society?: social exclusion and New Labour, Basingstoke, Palgrave Macmillan.

LEVITAS, R.; PANTAZIS, C.; FAHMY, E.; GORDON, D.; LLOYD, E. y PATSIOS, D. (2007): The multi-dimensional analysis of social exclusion, Londres, Social Exclusion Task Force, Cabinet Office.

MALGESINI, G. y GIMÉNEZ, C. (2000): Guía de conceptos sobre migraciones, racismo e interculturalidad, Madrid, Catarata.

MARSHALL, D. (2005): On the margins of inclusion: changing labour markets and social exclusion in London, Bristol, Policy Press.

MENA, I.R. (2007): Los gitanos y la venta ambulante. Una economía étnica singular, Sevilla, Centro de Estudios Andaluces.

MONTESINO, N. (2012): "Social disability: Roma and refugees in Swedish welfare", International Journal of Migration, Health, and Social Care, vol. 8, n- 3 , pp. 134-145.

MONTESINO, N. y OHLSSON, I. (2015): "The Prolonged Inclusion of Roma Groups in Swedish Society”, Social Inclusion, vol. 3, nํ5, pp. 126-136.

MINISTERIO DE SANIDAD, SERVICIOS SOCIALES E IGUALDAD; FUNDACIÓN SECRETARIADO GITANO y DALEPH (2016): Estudio-mapa sobre vivienda y población gitana. Madrid, Ministerio de Sanidad, Servicios Sociales e Igualdad.

NUN, J. (2001): Marginalidad y exclusión social, Buenos Aires, Fondo de Cultura Económica.

PAUGAM, S. (2007): Las Formas elementales de la pobreza, Madrid, Alianza.

PÉREZ ERANSUS, B. (2016): “Una propuesta de análisis de las políticas de inclusión", Revista Española del Tercer Sector, vol. 33, pp. 47-63.

PÉREZ ERANSUS, B. y MARTINEZ VIRTO, L. (2015): “LOS recortes en prestaciones y servicios sociales intensifican las desigualdades", en LAPARRA, M., La desigualdad y la exclusión que se nos queda: II informe CIPARAIIS sobre el impacto social de la crisis 2007-2014, Barcelona, Bellaterra, pp. 215-259.

PERKINS, D. (2010): “Activation and social inclusion: challenges and possibilities", Australian Journal of Social Issues, vol. 45, no 2, pp. 267-287.

PRESENCIA GITANA (1991): Informe sobre la cuestión gitana: orientaciones para un plan estatal de acciones prioritarias respecto a la problemática de la comunidad gitana española, Madrid, Editorial Presencia Gitana.

RíO, M.Á. (2014): “Políticas de realojo, comunidad gitana y conflictos urbanos en España (1980-2000)", Quid 16, vol. 4, pp. 34-61.

RODRÍGUEZ CABRERO, G.; AGUILAR, M.; ARRIBA, A.; CASAS, F.; LAPARRA, M. y MARBÁN, V. (2011): Servicios sociales y cohesión social. Madrid, Consejo Económico y Social

RODRÍGUEZ CABRERO, G.; GARCÍA SERRANO, C. y MARBÁN, V. (2009): La situación y perspectivas del trabajo autónomo, especialmente la venta ambulante de la población gitana, Madrid, Ministerio de Sanidad y Política Social.

RODRÍGUEZ, I. (2017): “Los desafíos de la intervención social con la comunidad gitana", Rediteia, vol. 49, pp. 47-60.

RORKE, B. (2014): “Roma integration and 'a normal way of living”, OpenDemocracy [en línea], disponible en: https://www.opendemocracy. net/can-europe-make-it/bernard-rorke/romaintegration-and-normal-way-of-living.

- (2015): "The end of a decade: what happened to Roma inclusion?", OpenDemocracy [en línea], disponible en: https://www.opendemocracy. net/can-europe-make-it/bernard-rorke/end-ofdecade-what-happened-to-roma-inclusion.

SIGONA, N. (2010): "Los gitanos en la Europa neoliberal: antigitanismo, pobreza y límites de la etnopolítica", en BRANDARIZ, J.Á. y PALIDDA, S., Criminalización racista de los migrantes en Europa, Granada, Comares, pp. 109-122.

SILVER, H. (2007): The process of social exclusion: the dynamics of an evolving concept, Providence, Brown University Chronic Poverty Research Centre.

STEWART, A. (2000): "Inclusion and exclusion in late modernity”, en ASKONAS P. y STEWART, A., Social inclusion: possibilities and tensions, Londres, Macmillan Press, pp. 55-72.

SZIRA, J. (2015): "What the "Roma Decade' Really Achieved", Open Society Foundations [en línea], disponible en: https://www.opensocietyfoundations.org/ voices/what-roma-decade-really-achieved.

TSOLAKIS, A. (2011): "Los gitanos en la agenda de la UE: principales hitos”, Gitanos: pensamiento y cultura, vol. 58, pp. 21-22.

UTRERA, J. (1987): “Jean-Pierre Liégeois. Un profesor holandés que asesora a la CE sobre la problemática gitana", El País, 8 de septiembre de 1987.

VARGAS, J. (2004): “Nuevos perfiles profesionales para minorías étnicas en la Sociedad del Conocimiento. El caso gitano", en TOURAINE, A.; WIEVIORKA, M. y FLECHA, R. Conocimiento e identidad. Voces de grupos culturales en la investigación social, Barcelona, El Roure, pp. 53-57.

VERMEERSCH, P. (2012): "Reframing the Roma: EU Initiatives and the Politics of Reinterpretation", Journal of Ethnic and Migration Studies, vol. 38, n- 8, pp. 1.195-1.212.

WILLEMS, W. (1997): In search of the true gypsy: from Enlightenment to Final Solution, London, Frank Cass. 